\title{
Assistência de Enfermagem em Sala de Parto e o Uso do Toque Terapêutico: um Caminho para a Humanização
}

\author{
Melo, Wesley Soares de; Colares, Deusalise Bento; Oliveira, Danila Paula C. de; \\ Holanda, Rose-Eloíse; Calderon, Carolina Jimenez; Veríssimo, Fco Arlysson da \\ Silva; Monteiro, Flávia Paula Magalhães \\ Faculdade Católica Rainha do Sertão — wesley_161@hotmail.com
}

Introdução: o preparo da gestante para o parto abrange a incorporação de cuidados e atividades que buscam oferecer à mulher a possibilidade de vivenciar esse momento de uma forma saudável, encarandoo como um processo fisiológico. Acredita-se que a prática do toque terapêutico atende aos anseios de uma atuação holística, baseada na visão integral do ser humano, comumente relatada na literatura de enfermagem. Objetivo: Investigar a utilização do toque terapêutico pela equipe de enfermagem que atua na sala de parto. Métodos: Pesquisa de natureza descritiva e exploratória com abordagem qualitativa, realizada em um hospital de referência na cidade de Banabuiú-Ceará. Os sujeitos do estudo foram: três auxiliares de enfermagem, três enfermeiros e cinco técnicos de enfermagem, totalizando 11 sujeitos. a coleta das informações foi realizada nos meses de março e abril de 2011, através de entrevista e se utilizou um formulário semi-estruturado. a pesquisa foi aprovada pelo Comitê de Ética e Pesquisa da Faculdade Católica Rainha do Sertão sob no de protocolo 20100189. Resultados: com base na leitura discursos dos entrevistados, foi possível definir 5 temas norteadores: Compreensão do significado do toque terapêutico, utilização do toque terapêutico na prática, benefícios do toque terapêutico para os profissionais que o realizam, benefícios do toque terapêutico para o paciente, e desejo de receber informação/capacitação relacionadas ao toque terapêutico. a definição do toque terapêutico, bem como a sua realização dentro do preconizado por seus idealizadores, é algo que requer conhecimento e técnica específicos. Porém, foi possível detectar através desse estudo, que a equipe de enfermagem detinha certa compreensão acerca do toque terapêutico, conhecia os seus benefícios e acreditava que o uso do mesmo poderia ser útil para amenizar o medo e a angústia das parturientes, como também consideravam essa prática um bom instrumento para estabelecer empatia. Pôde-se perceber que os participantes do estudo confundiam os conceitos do toque terapêutico com o toque instrumental, afetivo ou expressivo. Segundo os sujeitos, os benefícios da realização do toque para os pacientes eram: alivio da dor e redução da ansiedade. Os profissionais também identificaram benefícios do toque terapêutico para eles próprios: sentiam bem-estar, se sentiam úteis, gratificados e realizados ao aliviar a dor de alguém. o toque também possibilitava uma interação afetiva e fundamental para o desenvolvimento do cuidado individualizado. Todos os sujeitos desses estudos afirmaram que gostariam de receber informação/capacitação sobre o toque terapêutico e reconheciam a importância dessa técnica a ser utilizada em sala de parto. Conclusão: com bases nesses achados, acredita-se que os profissionais de saúde e em especial, os de enfermagem, precisam buscar conhecimento sobre o uso do toque terapêutico, preconizando um cuidado humanizado como pressuposto básico para uma assistência de qualidade.

Melo, Wesley Soares de; Colares, Deusalise Bento; Oliveira, Danila Paula C. de; Holanda, Rose-Eloíse; Calderon, Carolina Jimenez; Veríssimo, Fco Arlysson da Silva; Monteiro, Flávia Paula Magalhães. Assistência de Enfermagem em Sala de Parto e o Uso do Toque Terapêutico: um Caminho para a Humanização. In: Anais do Congresso Internacional de Humanidades \& Humanização em Saúde [= Blucher Medical Proceedings, num.2, vol.1]. São Paulo: Editora Blucher, 2014. ISSN 2357-7282 DOI 10.5151/medpro-cihhs-10461 